\title{
VEINTICINCO AÑOS DE DERECHO DE ASOCIACIÓN
}

\author{
ÁNGEL J. GÓMEZ MONTORO \\ Profesor Titular de Derecho Constitucional \\ Universidad de Navarra
}




\section{SUMARIO}

I. EL PLENO RECONOCIMIENTO DE UN DERECHO PROBLEMÁTICO. II. EL DERECHO DE ASOCIACIÓN COMO LIBERTAD INDIVIDUAL Y COMO GARANTIÁ OBJETIVA DEL PLURALISMO SOCIAL. III. ALGUNAS CUESTIONES PROBLEMÁTICAS SOBRE LA TITULARIDAD DEL DERECHO. IV. LA PLURALIDAD DE CONTENIDOS GARANTIZADOS POR EL DERECHO. 1. La dimensión individual del derecho. 2. La dimensión colectiva. V. LA ILICITUD DE LAS ASOCIACIONES Y SU CONTROL JUDICIAL. VI. DERECHO DE ASOCIACIÓN YTIPOS ASOCIATIVOS. LA FUNCIÓN DE LA LEY EN EL DESARROLLO DEL DERECHO DE ASOCIACIÓN. 


\title{
VEINTICINCO AÑOS DE DERECHO DE ASOCIACIÓN
}

POR

\author{
ÁNGEL J. GÓMEZ MONTORO \\ Profesor Titular de Derecho Constitucional \\ Universidad de Navarra
}

\section{EL PLENO RECONOCIMIENTO DE UN DERECHO PROBLEMÁTICO}

La aprobación de la Constitución de 1978 supuso el pleno reconocimiento del derecho de asociación, derecho que, a pesar de su proclamación en anteriores Textos constitucionales, se había visto sometido a lo largo de los siglos XIX y buena parte del XX a importantes restricciones y controles. Como es sabido, la animadversión hacia las asociaciones es una nota común del constitucionalismo europeo del siglo XIX que tiene su origen en el rechazo por parte de los revolucionarios franceses a los llamados "cuerpos intermedios", a los que se veía como un impedimento para la correcta relación entre ciudadano y nación, y cuya plasmación más notoria fue la celebre Ley le Chapelier que prohibió las asociaciones de trabajadores y declaró que "la aniquilación de todas las corporaciones de ciudadanos de un mismo estado o profesión era una de las bases fundamentales de la Constitución francesa». Similares medidas se adoptaron en los primeros años de nuestra Historia constitucional y, así, por Real Cédula de 29 de enero de 1793 y posterior Decreto de las Cortes de Cádiz de 8 de junio de 1812 se suprimieron los gremios y hermandades. Previamente, por Decreto de 14 de Decreto de 1811 se habían prohibido las asociaciones caritativas (Decreto de 14 de abril de 1811). 
Aunque por motivos distintos, esta actitud de reserva - cuando no de manifiesta hostilidad-hacia las asociaciones perduró durante todo el siglo XIX y buena parte del siglo XX. Se trata de un fenómeno bien conocido': el ejercicio del derecho de asociación $-y$ el de reunión, con el que irá parejo y del que no siempre se distinguirá- sirvieron de cauce para expresar el descontento frente al status quo, a través de los clubes y sociedades patrióticas, primero, y por medio de los incipientes partidos de izquierda, después. Las numerosas disposiciones que se adoptaron al respecto - muchas de ellas en el ámbito de la legislación penal - se inspiraban en unos principios marcadamente restrictivos. Por otra parte, la proclamación de este derecho en las Constituciones de 1869 y 1876 no supuso en modo alguno su efectividad pues durante todo el siglo XIX y buena parte del XX su ejercicio estuvo sometido a un estricto control gubernativo: ninguna asociación podia nacer sin el visto bueno de la autoridad gubernativa y ésta ostentaba importantes facultades de suspensión e, incluso, de disolución. Este estado de cosas, que se superó en buena parte de Europa en la primera mitad del siglo XX, se prolongó en España hasta bien entrada laTransición, pues la Ley de 1964 -que sin duda permitió un importante desarrollo de las asociaciones que podíamos denominar "no ideológicas" - excluía aquellas que tuvieran fines ilícitos y según su art. 1.3 por tales deberían tenerse "los contrarios a los Principios Fundamentales del Movimiento y demás Leyes fundamentales, los sancionados por las leyes penales, los que atenten contra la moral, el orden público y cualesquiera otros que impliquen un peligro para la unidad política y social de España», y esta prohibición iba acompañada de un fuerte control administrativo.

La situación cambió radicalmente con la entrada en vigor de la Constitución de 1978, que ha sido especialmente generosa en el reconocimiento del fenómeno asociativo. Superados los viejos prejuicios y temores y abandonada, asimismo, la visión marcadamente individualista del liberalismo burgués, el Texto constitucional - propio de un Estado Social y Democrático de Derecho - reconoce de una manera amplia, y con los únicos limites que señalan los apartados 2 y 5 de su art. 22, el derecho de asociación, cuyo régimen fundamental viene ya delimitado con bastante precisión en este precepto. Pero la Constitución contiene, además, numerosas referencias a determinados tipos

1 Véanse los trabajos de G. Rojas SÁnchez, Los derechos políticos de asociación y reunión en la España contemporánea (1811-1936), Pamplona, 1981, y B. OLÍAS DE LIMA GETE, La libertad de asociación en España (1868-1974), Madrid, 1977. 
de asociaciones: partidos políticos (art. 6), sindicatos (arts. 7 y 28), asociaciones empresariales (art. 7), comunidades religiosas (art. 16), organizaciones de consumidores y usuarios (art. 51.2), organizaciones profesionales (art. 52), y sociedades cooperativas (art. 129). Una pluralidad, por tanto, de tipos asociativos que, a pesar de las peculiaridades propias, son manifestación del derecho de asociación y tienen por ello su régimen general en el artículo $22 \mathrm{CE}$. Así lo ha señalado reiteradamente el Tribunal Constitucional para el que uel art. 22.1 C.E. reconoce el derecho de asociación sin referencia material alguna, de modo que este derecho se proyecta sobre la totalidad del fenómeno asociativo en sus muchas manifestaciones y modalidades (SSTC 67/1985, 23/1987 y 56/1995)" (STC 5/1996, FJ 6. ${ }^{\circ}$ ). El art. 22 CE es, por tanto, norma común a toda manifestación asociativa $y$, por ello mismo, contiene también el régimen jurídico básico de toda asociación $y$, en cuanto tal, supone el límite que necesariamente deberán respetar las leyes que regulen los distintos tipos asociativos. Toda asociación, cualquiera que sea su forma jurídica, nace de la libre voluntad de los socios (apartado 1), requiriéndose la inscripción a los solos efectos de publicidad (apartado 3), goza de la garantía judicial para su suspensión y disolución (apartado 4), no puede perseguir fines ni utilizar medios tipificados como delito (apartado 2) ni organizarse como una asociación secreta o paramilitar (apartado 5$)^{2}$.

Es quizás el grado de detalle del art. 22 CE en la configuración del derecho lo que explica que durante más de veinte años el derecho

2 Una cuestión de gran interés tanto práctico como teórico que sin embargo es aún sumamente discutida es la de si entre las entidades protegidas por el art. 22 están también las sociedades civiles y mercantiles. Los primeros autores que se ocuparon de este derecho (Fernández Farreres, Santamaria Pastor) rechazaron esta posibilidad; el Tribunal Constitucional no se ha pronunciado expresamente sobre el tema, aunque en algún obiter dictum ha insistido sobre todo en las diferencias entre las entidades con y sin ánimo de lucro (SSTC 23/1987, 94/1994 y 5/1996). La exclusión, también, la solución adoptada en la LODA. Sin embargo, cada vez son más los autores que, tanto en el ámbito del Derecho Público (Aguiar de Luque y Elvira Perales, Solozábal Echavarría) como Privado (Paz-Ares, Alonso Ledesma) vienen defendiendo un concepto amplio de asociación que, me parece, es el más adecuado a la realidad constitucional. Si el art. 22 CE protege la creación de todo tipo de entidades asociativas, con independencia de sus fines (lo que ha sido puesto de relieve en numerosas ocasiones por el Tribunal Constitucional), resulta difícil justificar la exclusión de la tutela constitucional por el hecho de que exista ánimo de lucro. Para un tratamiento más detenido del tema me remito a mi trabajo sobre "La titularidad de derechos fundamentales por personas jurídicas: un intento de fundamentación”, REDC, núm. 65,2002 , págs. 83 y ss. 
de asociación haya podido desenvolverse sin que se sustituyera la Ley de 1964 que debió, eso sí, reinterpretarse -y en muchos casos reconstruirse-desde los nuevos valores constitucionales. La nueva Ley Orgánica $1 / 2002$, de 22 de marzo, parece haber venido a satisfacer una necesidad muchas veces puesta de relieve, procediendo, de un lado, al desarrollo del derecho y regulando, de otro, el tipo asociativo básico. No obstante, y como intentaré explicar al final de este trabajo, la determinación del papel que corresponde a la ley en relación con este derecho es una de las cuestiones más complicadas y que en buena medida sigue abierta.

Por lo que a los desarrollos jurisprudenciales se refiere, cabe afirmar que el derecho de asociación no ha dado lugar a un cuerpo de doctrina especialmente abundante, lo cual parece indicar que no estamos ante un derecho especialmente problemático. Sin embargo, de manera gradual se han ido suscitando importantes cuestiones, algunas de las cuales han quedado relativamente clarificadas: tras las controversias sobre el papel del Registro (SSTC 85/1986, 291/1993 y 219/2001), los pronunciamientos del Tribunal Constitucional se centraron en la titularidad del derecho por los extranjeros (STC 115/1987), la espinosa cuestión de los derechos del socio frente a la asociación, y más en concreto, las garantías frente a la expulsión (SSTC 218/1988, 96/1994 y 56/1995) y en el alcance de la libertad negativa de asociación, cuestión suscitada en torno a las asociaciones y corporaciones de afiliación obligatoria (SSTC 5/1981, 67/1985, 131/1989, 132/1989, 183/1989, 244/1991, 113/1994, 179/1994, 107/1996, 194/1998 y 76/2003, entre otras). En los últimos años se han planteado cuestiones nuevas y no menos problemáticas entre las que destaca el alcance de la denominada dimensión colectiva del derecho de asociación (es decir, la tutela de la asociación en cuanto tal, con independencia de los derechos de los socios y a veces, incluso, contra ellos) (SSTC 96/1994, 104/1999 y 219/2001), la articulación entre la ley estatal y las leyes autonómicas en materia de asociaciones (STC 173/1998) y, más recientemente, el alcance de la ilicitud constitucional de las asociaciones, cuestión suscitada con motivo de la aprobación, y subsiguiente impugnación, de la Ley Orgánica de Partidos Políticos (STC 48/2003).

Y pareja ha trascurrido también la evolución de los tratamientos doctrinales. Tras la temprana y excelente monografía de G. Fernández Farreres $^{3}$ y el más breve pero relevante comentario al art. 22 de San-

3 Asociaciones y Constitución, Madrid, 1987 
tamaría Pastor ${ }^{4}$, el derecho de asociación no ha atraído el interés de los iuspublicistas hasta épocas ya relativamente recientes. En 1996 aparece el libro de de E. Lucas Murillo de la Cueva ${ }^{5}$, en 1997 el comentario al art. 22 CE de L. Aguiar y A. Elvira en la nueva edición de los Comentarios dirigidos por 0 . Alzaga ${ }^{6}$ y en el año 2000 un breve pero muy interesante trabajo de J.J. Solozábal ${ }^{7}$. Tras la entrada en vigor de la nueva Ley Orgánica han aparecido los completos comentarios de J. González Pérez y G. Fernández Farreres ${ }^{8}$ y poco a poco van publicándose trabajos sobre aspectos sectoriales.

En la páginas que siguen y de manera necesariamente sintética, intentaré hacer una exposición del derecho tal y como se ha ido perfilando en la jurisprudencia constitucional, deteniéndome fundamentalmente en los aspectos que se han presentado más problemáticos y en aquellas cuestiones relevantes que, en mi opinión, están aún necesitadas de clarificación. Con ello no se tendrá, sin embargo, una visión completa de lo que ha supuesto el derecho de asociación pues la realidad va mucho más allá de los problemas jurídicos y apunta a un gran desarrollo de todo tipo de entidades asociativas cuyo estudio debe quedar sin embargo al margen de este trabajo.

\section{EL DERECHO DE ASOCIACIÓN COMO LIBERTAD INDIVIDUAL Y COMO GARANTÍA OBJETIVA DEL PLURALISMO SOCIAL}

En una primera aproximación, el derecho de asociación garantiza la libertad de unirse con otras personas, de forma estable, para la consecución de determinados fines ("determinados" para cada asociación en concreto, pues una de las características más relevantes del derecho es, sin duda, la indeterminación general en cuanto a los fines que pueden ser perseguidos). Entendido así el derecho, poca argumentación se requiere para explicar su vinculación con la dignidad humana (art. 10.1 CE). No estamos, quizás, ante uno de los derechos

4 En F. Garrido Falla (dir.), Comentarios a la Constitución, Madrid, 1980 (la

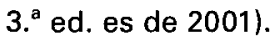

5 El derecho de asociación, Madrid, 1996.

6 "El derecho de asociación. Comentario al art. 22 CE», en Ó. Alzaga (dir.), Comentarios a la Constitución española de 1978, vol. II, Madrid, 1997.

7 "Asociación y Constitución", en Constitución y constitucionalismo hoy. Cincuentenario del Derecho Constitucional Comparado de Manuel Garcia-Pelayo, Caracas, 2000.

8 Derecho de Asociación. Comentarios a la Ley Orgánica 1/2002, de 22 de marzo, Madrid, 2002. 
que integran el círculo más estrechamente vinculado con esa dignidad, al que pertenecen, sin duda, el derecho a la integridad física (vida, derecho a no sufrir torturas), la libertad en sentido estricto o el derecho a la integridad moral (derecho a no sufrir tratos inhumanos ni degradantes, libertad de conciencia y religiosa). Sin embargo, se trata de un derecho íntimamente unido a una dimensión esencial del hombre que es su sociabilidad. Como ha destacado J. J. Solozábal «la idea de hombre cuya dignidad se protege $y$ de la que parte el constituyente no es la correspondiente a un ser aislado o mónada social, sino ligado, por decirlo así, a la convivencia en sociedad" ${ }^{9}$. La libertad de asociación integra, junto con las de expresión y reunión, un determinado status collectivus de la persona.

Más clara es aún la vinculación de la libertad asociativa con el libre desarrollo de la personalidad al que se refiere también el art. 10.1 $\mathrm{CE}$. Ese desarrollo, al que en buena medida están orientados los derechos fundamentales, exige la existencia y garantía de realidades asociativas. Estas son, por una parte, manifestación de la dimensión social del hombre y, al mismo tiempo, consecuencia de su limitada capacidad para conseguir ciertos fines. La libertad implica la facultad de organizarse para la consecución de los fines que no están prohibidos por el ordenamiento, y entre las formas de organización está, sin ninguna duda, la unión ocasional o estable-con otras personas; lo que la libertad permite hacer al hombre aisladamente, se lo permite también hacer junto con otros. Asociarse es, por tanto, una forma elemental de expresión de la libertad de actuación y, al garantizarse el derecho de asociación, se garantiza, al mismo tiempo, el libre desarrollo de la personalidad "en" y "a través" de los grupos sociales.

Pero el art. 22 CE es, además - en palabras de nuestro Tribunal Constitucional-, "uno de los elementos estructurales básicos del Estado Social y Democrático de Derecho" (STC 173/1998, 8. $^{\circ}$. Junto a su vertiente subjetiva, la libertad de asociación contiene en la fórmula acuñada por el Tribunal Constitucional Federal alemán: el principio de la libre creación de grupos sociales (das Prinzip freier sozialer Gruppenbildung $)^{10}$. Dicho en otros términos, el derecho de asociación no sólo

9 Voz "Dignidad de la persona", en Enciclopedia Jurídica Básica, Madrid, 1995, vol. Il, pág. 2489. Véase también, de este mismo autor, "Asociación y Constitución", cit., pág. 478.

10 Estas palabras del Tribunal Constitucional Federal alemán (BVerfGE 38, 281,$303 ; 50,290,354 ; 80,244,252$ ) son perfectamente trasladables a nuestro sistema constitucional. 
garantiza una libertad individual sino que, al mismo tiempo, permite la creación de grupos que son esenciales en un Estado Social y Democrático. Esta esencialidad se ha puesto con frecuencia de relieve respecto de los partidos políticos: sin partidos es difícil que haya pluralismo y sin éste no puede existir la democracia (STC 86/1986, FJ $2 .^{\circ}$, por todas). Pero esta "dimensión objetiva» del derecho no debe, sin embargo, reducirse a la faceta de participación democrática, por muy importante que ésta sea; de hecho, trasciende el ámbito del Estado para incidir en el de la sociedad misma. La libertad asociativa garantiza no sólo el pluralismo político e ideológico, sino el religioso, el cultural, el social y el económico, y permite la intervención de los grupos en cualesquiera asuntos públicos. Sólo ella hace posible "la autoorganización libre de la sociedad que contempla nuestra Constitución" 11.

\section{ALGUNAS CUESTIONES PROBLEMÁTICAS SOBRE LATITULARIDAD DEL DERECHO}

Desde el punto de vista de la titularidad del derecho la cuestión más complicada y todavía por resolver es, sin duda, la relativa a los extranjeros. El problema se suscitó con motivo de la Ley Orgánica $7 / 1985$, de 1 de julio, de derechos y libertades de los extranjeros en España, cuyo art. 8 les reconocía el derecho de asociación (apartado 1) pero preveía al mismo tiempo la posibilidad de suspensión administrativa de las asociaciones promovidas o integrada mayoritariamente por extranjeros (apartado 2). Con motivo del recurso interpuesto por el Defensor del Pueblo afirmó elTribunal Constitucional que "debe admitirse que, de acuerdo a sus propios términos, el art. 22 de la Constitución, en contraste con otras Constituciones comparadas, reconoce también directamente a los extranjeros el derecho de asociación" (STC 117/1985, FJ $3 .^{\circ}$ ) y entendió que si bien «el art. 13.1 de la Constitución reconoce al legislador la posibilidad de establecer condicionamientos adicionales al ejercicio de derechos fundamentales por parte de los extranjeros $(. .$.$) ha de respetar, en todo caso, las prescripciones cons-$ titucionales, pues no se puede estimar aquel precepto permitiendo que el legislador configure libremente el contenido mismo del derecho, cuando éste ya haya venido reconocido por la Constitución directamente a los extranjeros, a los que es de aplicación también el mandato contenido en el art. 22.4 de la Constitución». Esta decisión dio

1 J .J. Solozábal Echavarría, "Asociación y Constitución», cit., pág. 479. 
lugar a un voto particular de los Magistrados Rubio Llorente, Tomás y Valiente y García Mon pues, en su opinión, el legislador se habia movido dentro de los márgenes que le otorga art. 13.1 CE; para ellos, las limitaciones del legislador al establecer diferencias de trato respecto de los extranjeros "no derivan de los enunciados constitucionales que consagran las libertades públicas de los españoles, sino de los Tratados internacionales, bien porque éstos imponen un trato especial para los nacionales de Estados determinados, bien sea porque obligan al Estado español en relación con todos los extranjeros, sea cual fuere su origen».

La cuestión volvió a plantearse con motivo de la LO 4/2000, sobre derechos y libertades de los extranjeros en España y su integración social, y sobre todo con la reforma que en la misma introdujo la LO 8/2000. La nueva Ley Orgánica reconoce a los extranjeros el derecho de asociación "conforme a las leyes que lo regulan para los españoles» (art. 8), pero tras la reforma introducida por la LO 8/2000, y al igual que en el caso de otros derechos, se exige para su ejercicio la autorización de estancia o residencia en España. La reforma dio lugar a una encendida $-y$ bien conocida-polémica tanto política como jurídica. Desde esta última perspectiva se han suscitado dudas sobre la constitucionalidad de la reforma. Por lo que a los derechos de reunión y asociación se refiere, se ha insistido en que se trata de derechos que expresan la sociabilidad de la persona, necesarios para poder comunicarse en libertad, antes que derechos de naturaleza política, lo que les vincularía de manera muy inmediata con la dignidad de la persona e impediría diferencias de trato como las introducidas. Otros insisten, por el contrario, en que no puede olvidarse que el art. $13 \mathrm{CE}$ hace un llamamiento expreso a los tratados internacionales y la ley para que precisen los términos en los que los extranjeros gozan en España de las libertades públicas, y que de la jurisprudencia constitucional existente hasta la fecha no se deduce una exigencia de total equiparación en el disfrute de esas libertades. La cuestión deberá ser despejada por elTribunal Constitucional, ante quien se encuentra recurrida la Ley ${ }^{12}$.

Menos problemas suscita la titularidad del derecho de asociación por personas jurídico-privadas. Éstas no sólo nacen en gran parte de

12 Sobre estas cuestiones me permito remitir a mi trabajo «Titularidad de Derechos», en M. ARAgón (coord.), Temas básicos de Derecho Constitucional, Madrid, 2001, págs. 119 y ss.). 
los casos del ejercicio de la libertad asociativa sino que, al mismo tiempo, son ellas mismas titulares del derecho. Es bien sabido que nuestro Tribunal Constitucional ha admitido que las personas jurídicas son también titulares de derechos fundamentales siempre que, por su naturaleza, les sean aplicables ${ }^{13}$ y en el caso del derecho de asociación, no hay ninguna duda sobre dicha aplicabilidad ${ }^{14}$. Así lo ha venido a confirmar la LODA cuyo art. 3 dispone que "podrán constituir asociaciones, y formar parte de las mismas, las personas físicas y las personas jurídicas». Resulta, por el contrario, criticable la inclusión de las personas jurídico-públicas entre los titulares del derecho que se hace en ese mismo artículo (y previamente en el art. 2.6). Como es sabido, el Tribunal Constitucional viene rechazando sistemáticamente que las personas jurídicas de Derecho Público puedan ser titulares de derechos fundamentales (con la salvedad, no exenta de problemas, de los derechos del art. $24 \mathrm{CE}$ ), por lo que este precepto no puede significar una atribución de "el derecho de asociación» (al menos del derecho constitucional de asociación) sino un reconocimiento legal - una autorización, incluso - de que las entidades públicas pueden también asociarse.

\section{LA PLURALIDAD DE CONTENIDOS GARANTIZADOS POR EL DERECHO}

Como ocurre con tantos otros derechos, la libertad de asociación incluye en su ámbito constitucionalmente protegido una pluralidad de facultades que, además, tienen orígenes históricos distintos y que se han ido perfilando también de manera progresiva en la jurisprudencia constitucional. Unas se refieren a la dimensión individual del derecho, que incluye una faceta positiva, la libertad de asociarse, con todo lo que ello implica $-y$ otra negativa la libertad de no asociarse - . Pero

13 Sobre la titularidad de derechos fundamentales por personas juridicas me remito, asimismo, a mis trabajos "La titularidad de derechos fundamentales por personas juridicas (Análisis de la jurisprudencia del Tribunal Constitucional español)", Cuestiones Constitucionales, núm. 2, 2000, págs. 23 y ss.; y "La titularidad de derechos fundamentales por personas jurídicas: un intento de fundamentación", cit.

14 Así parece entenderlo, desde luego, el Tribunal Constitucional, que, aunque no ha realizado un pronunciamiento expreso sobre el tema, ha reconocido el derecho de las asociaciones deportivas a formar parte de federaciones y a crear nuevas asociaciones (STC 67/1985, FJ $4 .^{\circ}$ ) y el derecho de los partidos políticos a formar federaciones (STC 168/1989). 
al mismo tiempo, y es ésta una peculiaridad del derecho de asociación en la que necesariamente se ha de insistir, del ejercicio del derecho surge una nueva entidad - la asociación-, que también viene protegida por el art. $22 \mathrm{CE}$; estas facultades integran la llamada dimensión colectiva del derecho. Ambas dimensiones se relacionan estrechamente $y$, aunque en ocasiones pueden surgir colisiones entre ellas ${ }^{15}$, la tutela de la organización es imprescindible si no se quiere dejar vacío el contenido individual del derecho.

\section{La dimensión individual del derecho}

\section{a) Contenido positivo}

Desde el punto de vista individual, el art. 22 CE tiene, en primer lugar, un contenido positivo: la libertad de asociarse, con todo lo que ello supone. Esta es, quizás, la faceta menos problemática del derecho o, al menos, ha motivado escasos pronunciamientos delTribunal Constitucional. Algunas de las facultades que integran el derecho se pueden ejercer de manera individual (aunque presuponen, en todo caso, la existencia previa de una asociación); otras, han de ser ejercidas necesariamente en colaboración con otro u otros titulares. Al primer tipo pertenece la libertad de integrarse en una asociación, garantizada frente al poder público, sin que exista un derecho frente a la asociación misma: la efectiva incorporación sólo es posible si se cumplen los requisitos previstos en los estatutos y se es aceptado por el órgano al que estos atribuyan la decisión sobre la admisión de nuevos socios. El acto de incorporación supone, al mismo tiempo, la manifestación por parte del nuevo socio de que asume los fines, los derechos y las cargas previstos en los estatutos: «El acto de integración en una asociación - se afirma en la STC $218 / 1988$, FJ $2 .^{\circ}-(\ldots)$ consiste, como se ha dicho, en un acto por el cual el asociado acepta los estatutos y se integra en la unidad no sólo jurídica sino también moral que constituye la asociación".

Otras facultades, aún siendo también de titularidad individual, sólo pueden ser ejercidas en concurrencia con otros titulares, y entre ellas destaca la libertad quizás más significativa: la de constituir una

15 No son pocos, en efecto, los casos en los que asociación y asociado aparecen enfrentados en un proceso, invocando ambos la tutela de su libertad asociativa. 
asociación. En palabras del Tribunal Constitucional, el derecho de asociación garantiza "la posibilidad de los individuos de unirse para el logro de "todos los fines de la vida humana", y de estructurarse y funcionar el grupo asi formado libre de toda interferencia estatal" (STC $\left.115 / 1987, \mathrm{FJ} 3 .^{\circ}\right)$. Esta libertad incluye la capacidad de decisión sobre la creación o no del nuevo ente pero tutela, además, la decisión sobre el momento de llevarla a cabo, sobre el nombre, la sede, el fin y la forma, extremos estos que se concretan en los estatutos. Como ha puesto de relieve nuestroTribunal Constitucional, el acto por el que se crea una asociación y la aprobación de los estatutos vienen a fundirse en uno solo (STC 104/1999, FJ 4. ${ }^{\circ}$.

\section{b) Contenido negativo}

Junto a la libertad positiva existe una libertad negativa que, aunque no mencionada de forma expresa en el art. $22 \mathrm{CE}$, ha sido admitida por elTribunal Constitucional desde sus primeras resoluciones: «de acuerdo con el art. 10.2 de la Constitución - se afirma en la STC $67 / 1985, \mathrm{FJ} 3 .^{\circ}-$, las normas relativas al derecho de asociación han de ser interpretadas de conformidad con la Declaración Universal de Derechos Humanos y los tratados y acuerdos internacionales sobre las mismas materias ratificados por España. Este criterio interpretativo permite afirmar que el derecho de asociación comprende tanto la libertad positiva de asociación como la negativa de no asociarse".

La libertad negativa de asociación garantiza el derecho a no constituir una asociación, a no afiliarse a ninguna de las existentes y a abandonar aquéllas de las que se sea miembro (art. 2.3 LODA). De estos contenidos es el derecho a no afiliarse el que ha suscitado más problemas, y como no está en manos de los particulares el obligar a nadie a asociarse, la cuestión se ha planteado básicamente en relación con la capacidad del poder público de crear organizaciones a las que necesariamente deban pertenecer determinados colectivos. Esta posibilidad ha sido admitida, con carácter general, por nuestro Tribunal Constitucional: "la Constitución - se afirma en la STC 179/1994, FJ 5. ${ }^{\circ}-(\ldots)$ admite expresamente la legitimidad de la genéricamente llamada Administración corporativa, es decir, de las «corporaciones no territoriales", "corporaciones sectoriales de base privada" o "entes públicos asociativos", entendiendo por tales, en términos generales, a diversas agrupaciones sociales, creadas por voluntad de la ley en función de diversos intereses sociales, fundamentalmente profesionales, dotadas frecuentemente de personalidad jurídico-pública, $y$ acompañadas, tam- 
bién frecuentemente, del deber de afiliarse a las mismas». Estas entidades no son asociaciones a los efectos del art. $22 \mathrm{CE}$, por lo que ni existe un derecho de los ciudadanos a crearlas o a que los poderes públicos las creen, ni a ellas les es aplicable el régimen propio de las asociaciones (por todas, SSTC 89/1989, 131/1989, 139/1989, 244/1991, $194 / 1998$ y 76/2003). Sin embargo, esta conclusión no ha impedido al Tribunal Constitucional entender que cuando se impone la afiliación obligatoria se afecta al derecho de asociación en su vertiente negativa, afectación que podrá ser legítima cuando existan fines públicos constitucionalmente tutelados que pueden justificar la limitación de esa libertad. ElTribunal ha insistido en la excepcionalidad de este tipo de entidades y ha señalado "tres criterios mínimos y fundamentales" (STC 113/1994, FJ $11 .{ }^{\circ}$ ) que permiten determinar cuándo una asociación de creación legal, de carácter público y adscripción obligatoria, puede superar un adecuado control de constitucionalidad: en primer lugar, no cabe afectar a la libertad de asociación en sentido positivo, de manera que la adscripción obligatoria no puede ir acompañada de una prohibición o impedimento de asociarse libremente; en segundo lugar, el recurso a esta forma de actuación administrativa no puede convertirse en regla, pues se alteraría el sentido de un Estado Social y Democrático de Derecho basado en el valor superior de la libertad (art. 1.1 C.E.) y que encuentra en el libre desarrollo de la personalidad el fundamento de su orden político (art. 10.1 C.E.); por último, la adscripción obligatoria debe encontrar suficiente justificación, ya sea en disposiciones constitucionales, ya en las características de los fines de interés público que persigan, de las que resulte, cuando menos, la dificultad de obtener tales fines sin recurrir a la adscripción forzosa a un ente corporativo.

Son relativamente numerosas las ocasiones en las que el Tribunal ha debido examinar si concurrían los intereses públicos que justificaban la afiliación obligatoria prevista en diversas regulaciones normativas y en un porcentaje muy alto de supuestos ha concluido que no existía lesión del art. $22 \mathrm{CE}^{16}$. En el caso de Colegios Profesionales ha admitido la constitucionalidad de la afiliación obligatoria de Abo-

16 Las dificultades para llevar a cabo una ponderación de este tipo se evidenciaron en las dos sentencias sobre las Cámaras de Comercio, Industria y Navegación; en la primera de ellas (STC 79/1994), el Tribunal concluyó -con la opinión en contra de tres de los Magistrados - que las Bases Cuarta y Quinta de la Ley de 29 de junio de 1911 y del art. 1 del Real Decreto-ley de 26 de julio de 1929, en cuanto implican la adscripción forzosa a las Cámaras Oficiales de Comercio, Industria y Navegación, eran contrarias al art. 22; en la segunda (STC 107/1996), declaró sin 
gados (STC 123/1987), Médicos (STC 131/1989 y 35/1993), Administradores de Fincas (STC 74/1994) y Profesores de Educación Física (194/1998) y sólo ha negado su legitimidad en el caso de Secretarios, Interventores y Tesoreros de la Administración Local debido a que todos prestan sus servicios en la Administración y el poder público ha regulado de manera detenida tanto su actividad como su estatuto (SSTC 76, 96 y 108 de 2003). Ha declarado, asimismo, compatible con el art. 22 CE la pertenencia forzosa a mutualidades (STC 244/1991) y, como acaba de señalarse, a las Cámaras de Comercio (STC 107/1996). Consideró, por el contrario, inconstitucional la afiliación obligatoria a las Cámaras Agrarias (SSTC 132/1989 y 139/1989) y a las Cámaras de la Propiedad Urbana (STC 113/1994).

Aunque no es posible detenerse en esta cuestión, sí cabe dejar apuntada la pregunta sobre si éste era el único camino que se abría al Tribunal Constitucional y si, en todo caso, era el más adecuado y ello porque no deja de llamar la atención que algo tan importante como la dimensión negativa de un derecho de libertad ceda ante intereses de perfiles en muchos casos muy difusos. Cabe, por ello, preguntarse si no hubiera sido mejor seguir la solución adoptada por el Tribunal Constitucional Federal alemán que, siguiendo a parte de la doctrina de aquel país, ha descartado que la incorporación forzosa a entidades de Derecho público afecte al art. $9 \mathrm{GG}$, en el que se garantiza el derecho de asociación. El razonamiento en que se basa esta afirmación es bastante simple: el art. $9 \mathrm{GG}$ garantiza únicamente la libertad de crear, entrar o salir de asociaciones privadas, en consecuencia, la libertad de asociación sólo está en juego cuando se trata de entidades de esta naturaleza ${ }^{17}$. Esto no quiere decir que entonces el legislador no tenga límites para la creación de corporaciones de pertenencia forzosa, pero el canon de control sería el de la libertad de profesión u oficio que garan-

embargo (esta vez con el parecer discrepante de cuatro de sus Magistrados) la constitucionalidad de los arts. 6, 12 y 13 de la Ley 3/1993, de 22 de marzo, Básica de las Cámaras Oficiales de Comercio, Industria y Navegación, que establecian, asimismo, la afiliación obligatoria.

17 Véanse, por ejemplo, BVerfGE 10, 89, 102; 11, 105, 126; 12, 319, 323; 38 , 281,$297 ; 50,290,354 ;$ y $78,320,329$. El mismo razonamiento ha sido asumido por el Tribunal Europeo de Derechos Humanos que, en los casos Le Compte - Sentencia de 23 de julio de 1981 - y Albert y Le Compte - Sentencia de 10 de febrero de 1983 - sostuvo que, puesto que los Colegios profesionales no son asociaciones, con la colegiación obligatoria no resulta afectado el art. 11.1 del Convenio, por lo que el Tribunal tampoco consideró necesario entrar a examinar si la causa de la limitación del derecho era o no de las previstas en el apartado 2 del citado precepto. 
tiza el art. $35 \mathrm{CE}$, derecho respecto del cual el legislador goza de un amplio margen de decisión.

\section{La dimensión colectiva}

La idea de una vertiente colectiva del derecho de asociación es relativamente novedosa, lo que no obsta para que se la pueda considerar como una exigencia ineludible del derecho pues de poco serviría garantizar la libertad de creación de entidades asociativas si éstas, una vez creadas, quedaran al albur del poder público. Se ha podido afirmar, por ello, que el derecho de autoorganización, al que en buena parte se reconduce la dimensión colectiva del derecho de asociación, no es sino una derivación de los derechos individuales de los miembros, que se orienta a darles eficacia más allá del momento constitutivo. NuestroTribunal Constitucional se ha referido en algunas ocasiones a esta dimensión de la libertad asociativa, aunque no hay todavía un cuerpo de doctrina suficientemente relevante y la jurisprudencia no deja de mostrar ciertos titubeos en cuanto a su alcance. Así, en la STC 219/2001, tras citar los precedentes sobre la materia (SSTC $218 / 1988,5 / 1996$ y 104/1999), se afirma que «ningún obstáculo existe, en principio, para que una asociación, en cuanto persona jurídica distinta de las personas físicas que son sus asociados $-y$, por tanto, centro autónomo de relaciones y consecuencias jurídicas - pueda invocar en su favor el derecho que el art. 22 CE reconocen, pero se insiste, igualmente, en que "el art. 22 CE no dispone expresamente una tutela simétrica de los socios y de la asociación" (FJ 4..$^{\circ}$ ). Estas vacilaciones parecen responder al temor de que, como con alguna frecuencia se recuerda, el reforzamiento de la tutela de la asociación lleve consigo la limitación de los derechos del socio; socio y asociación se verían enfrentados, invocando cada uno en su defensa la misma libertad asociativa ${ }^{18}$. Es difícil, sin embargo, extraer concretas consecuencias juridicas de la "asimetría» a que se refiere elTribunal: es evidente que no existe una posición simétrica, pues las concretas facultades tuteladas en uno y otro caso son distintas, pero de ahí no puede derivarse una prevalencia incondicional de los derechos del socio. De hecho, no debe desconocerse que la controversia entre asociación y socios puede, en realidad, reconducirse a un conflicto de intereses entre los titulares del

18 La cuestión está tratada de manera ejemplar en el trabajo de J. M. BILBAo Ubillos, Libertad de asociación y derechos de los socios, Valladolid, 1997. 
derecho que forman la mayoría y los intereses del socio o socios que consideran que aquélla no ha respetado sus derechos.

\section{a) El problema de la inscripción registral}

Una primer manifestación de esa dimensión colectiva es el derecho de la nueva asociación a recibir reconocimiento por el ordenamiento jurídico, lo que plantea dos cuestiones que se ha presentado especialmente polémicas: el papel del Registro y la adquisición de personalidad jurídica. De acuerdo con el art. 23.2 CE «las asociaciones constituidas al amparo de este artículo deberán inscribirse en un registro a los solos efectos de publicidad". Esta redacción, ciertamente no muy afortunada, ha suscitado dudas sobre las consecuencias jurídicoconstitucionales de la inscripción y, a sensu contrario, las de su omisión. Es este un problema que ha dado lugar a numerosas páginas $y$, de hecho, parece haber sido durante muchos años «el» problema - aunque más teórico que práctico- del derecho de asociación. En mi opinión, estamos en buena medida ante un problema aparente que sólo se entiende desde nuestra no muy feliz experiencia histórica, también la más reciente. Como es sabido, el Registro fue precisamente el medio a través del cual el Ejecutivo controlaba las asociaciones; la obligación de registrarse (art. 5 de la Ley de 1964), unida a las numerosas causas de ilicitud, enunciadas además de forma estudiadamente vaga (art. 1.3), hacian de la creación de una asociación una actividad más próxima a aquellas sometidas a autorización previa que a las que constituyen el ejercicio de un derecho. En momentos de normalidad constitucional como los que - al menos en muchos aspectos - vivimos, el Registro ha dejado de ser un riesgo para el derecho (y así parece demostrarlo la experiencia): resulta claro que ni el funcionario que registra tiene libertad para realizar un control ideológico de las asociaciones (no podría hacerlo sin incurrir en un delito) ${ }^{19}$, ni los que crean una asociación pueden pretender que sea reconocida como tal en el tráfico jurídico y que acceda a alguno de los distintos tipos ofrecidos por el legislador sin inscripción alguna en el correspondiente Registro y sin la previa comprobación de que reúne los requisitos legalmente exigidos para ello.

Es verdad que la asociación nace por la libre concurrencia de las voluntades de quienes se unen y no por la inscripción en el Registro,

Véanse los arts. 539 y 542 del Código Penal. 
y por ello la falta de inscripción no puede equipararse a la no existencia de la nueva entidad. Sin embargo, esto no significa que al legislador le esté vedado exigir la inscripción para que la asociación pueda adoptar una determinada forma jurídica, para acceder a determinados beneficios (por ejemplo, reconocimiento como de utilidad pública o los que se derivan del Registro de asociaciones religiosas) o a subvenciones ${ }^{20}$, para garantizar la separación de patrimonios y la limitación de responsabilidad, etc. En realidad, la seguridad de terceros que pueden entablar relaciones con la nueva entidad asociativa es lo que no sólo permite, sino que exige del legislador el establecimiento de un Registro en el que obren los datos que aquéllos tienen derecho a conocer $y$ autoriza a sus titulares a llevar a cabo un control de legalidad que asegure el cumplimiento de los requisitos reglados.

Para buena parte de la doctrina, el exacto alcance del mandato de inscripción registral del art. 22.3 CE sólo se entiende desde la perspectiva de la adquisición de personalidad jurídica por la asociación. Esta - se afirma - nace de la libre voluntad de los socios, pero sólo adquiere personalidad jurídica cuando se inscribe en el correspondiente Registro ${ }^{21}$. En apoyo de esta tesis se ofrecen al menos dos argumentos: de un lado, la personalidad es algo no intrínseco a la asociación, se trata de un plus que puede otorgar el ordenamiento jurídico bajo las condiciones que estime oportunas; en segundo lugar, se afirma, la personalidad requiere siempre publicidad, por lo que no sería lógico su reconocimiento a aquellas asociaciones y sociedades no inscritas. En mi opinión, la solución del problema pasa por definir qué se entiende por personalidad jurídica, lo cual, como es bien sabido, no es tarea fácil. En todo caso, y si se acepta que del ejercicio del derecho de asociación nace, por el simple perfeccionamiento de la voluntad de los socios, un ente distinto de ellos que, en cuanto tal, tiene

20 En este caso, puede exigirse, además, la inscripción en un Registro específico. Así lo señaló el Tribunal en la STC 15/1989, en cuyo fundamento jurídico $7 .^{\circ}$ afirma que «la exigencia de la necesaria inscripción de las asociaciones de consumidores y usuarios en un libro-registro llevado en el Ministerio de Sanidad y Consumo no puede estimarse inconstitucional, dado que esa exigencia o carga se vincula directamente a la posibilidad de acceder a los beneficios que prevea la propia Ley y las disposiciones reglamentarias y concordantes" (en el mismo sentido se pronunció la STC 133/1992, FJ 6..$^{\circ}$.

21 Ésta es la postura, por ejemplo, de J. A. SANTAMARIA PASTOR, “Comentario al art. 22 CE», cit., págs. 501 y ss.; G. FeRnÁndeZ FARRERES, Asociaciones y Constitución, cit., págs. 89 y ss.; y L. AguiAR DE LuQue y A. ELVIRA PERALES, "El derecho de asociación. Comentario al art. $22 \mathrm{CE»,} \mathrm{cit.,} \mathrm{págs.} 617$ y ss. 
vocación de ser reconocido por el Derecho, parece necesario entender que ello comporta un mínimo de personalidad jurídica. La entidad así creada puede no tener mayores pretensiones $y$, en consecuencia, no solicitar inscripción en ningún Registro, como de hecho ocurre con buena parte de las sociedades civiles. La asociación podrá, sin duda, operar en el tráfico como tal; ahora bien, no gozará de las ventajas que aporta la inscripción registral y, por tanto, no podrá alegar su carácter de persona jurídica autónoma en contra de los intereses de terceros (lo que no le impedirá probar, en su caso, que su existencia era conocida por esos terceros y que en esa condición entabló con ellos determinadas relaciones juridicas). Ésta es la solución por la que ha optado - en mi opinión acertadamente - la LODA. En su art. 5.2 vincula la adquisición de personalidad jurídica y la plena capacidad con el otorgamiento del acta fundacional (que podrá hacerse en documento público o privado), configurándose el Registro como una garantía tanto para terceros como para sus propios miembros (art. 10.2). En el caso de que la inscripción no se haya llevado a cabo, los promotores de la asociación responden personal y solidariamente frente a terceros, y todos los socios responden también de forma solidaria por las obligaciones contraídas por cualquier de ellos frente a terceros, siempre que hubieran manifestado actuar en nombre de la asociación (art. 10.4) ${ }^{22}$.

Interesa, por último, destacar que la jurisprudencia constitucional más reciente ha dado un nuevo e interesante enfoque a la inscripción registral, entendiéndola como un derecho de la asociación más que como una carga: "la inscripción - se afirma en la STC 219/2001, fundamento jurídico $5 .^{\circ}$ - no es sólo una carga de la asociación ya creada, sino también una prestación debida por la Administración encargada del correspondiente Registro, a fin de que la libertad de asociación se realice plenamente. Se trata, incluso, de una prestación administrativa cuya realización defectuosa puede resultar lesiva del derecho" ${ }^{23}$. Esta idea ha encontrado reflejo en el art. 24.1 LODA, según el cual "el derecho de asociación incluye el derecho a la inscripción en el Registro de Asociaciones competente".

22 Una visión más crítica de la regulación de la LODA en A. J. QUESADA SÁNCHEZ, "La personalidad jurídica de la asociación en la Ley Orgánica 1/2002, de 22 de marzo", Actualidad Civil, núm. 11, 2003, págs. 273 y ss.

23 A la inscripción como derechos se refieren también la STC 46/2001 y la STS de 30 de junio de 1994. Véase, sobre el tema, J.A. MONTILLA MARTOS, "La inscripción registral de las asociaciones en la Constitución", REP, núm. 92, 1996, págs. 178 y ss. 


\section{b) La autonomía organizativa}

Pero la dimensión colectiva del derecho va más allá del nacimiento de la asociación e implica, fundamentalmente, la aptitud de la organización creada en ejercicio del derecho para desenvolverse como tal; garantiza su autonomía organizativa y su capacidad funcional. El derecho de asociación protege no sólo el derecho "a» (crear) una asociación sino también el derecho "en" la asociación. Quedan, por tanto, dentro del ámbito constitucionalmente garantizado todas aquellas actuaciones de los titulares de la organización que se ordenan a su subsistencia y a su capacidad de funcionamiento. Esto incluye la autonomía normativa y la autonomía organizativa. Esta última no está desde luego exenta de límites, pues el apartado $5 \mathrm{del}$ art. 22 CE excluye a las asociaciones paramilitares y secretas. Esta exclusión, claramente inspirada en el art. 18, párrafo $2 \mathrm{Cl}$, ha sido generalmente criticada, sobre todo por su escasa utilidad 24 . Por otra parte, ambos términos no aluden sólo a aspectos organizativos, aunque estos resultan, sin duda, esenciales para determinar cuándo estamos en presencia de una organización de uno u otro tipo. En todo caso, no ha presentado hasta el momento especiales problemas prácticos ni parece fácil que los suscite en el futuro.

Más complicada se presenta la cuestión de hasta qué punto puede el legislador limitar el derecho de autoorganización mediante la exigencia de formas organizativas que garanticen la democracia interna. La exigencia de una organización y funcionamiento internos democráticos es impuesta por la Constitución a partidos políticos (art. 6), sindicatos y organizaciones empresariales (art. 7), Colegios profesionales (art. 36) y organizaciones profesionales (art. 52). La ausencia de un expreso soporte constitucional no impide que el legislador pueda extender esta misma exigencia a otro tipo de entidades ${ }^{25}$. Pero debe-

24 Véanse, por ejemplo, J. A. SANTAMARÍA PASTOR, "Comentario al art. 22 CE", cit., págs. 497 y ss.; I. DE OTTO, Defensa e la Constitución y partidos políticos, Madrid, 1985, págs. 72 y ss.; y, más recientemente, J. González Pérez y G. Fernández FarreRES, Derecho de Asociación, cit., pág. 125.

25 El Tribunal Constitucional ha señalado que el mandato de democracia interna no puede hacerlo, en todo caso, el legislador autonómico. Se trata - se afirma en la STC 173/19998, FJ 12.: - wde un desarrollo directo de un elemento esencial para definir la libertad de autoorganización de las asociaciones, por lo que solamente las Cortes Generales mediante Ley Orgánica tienen competencia para pronunciarse sobre si las asociaciones deben organizarse y funcionar democráticamente o si, por el contrario, los estatutos de la asociación pueden establecer libremente otros modos de organización y funcionamiento". 
rán existir razones de suficiente peso $y$, en todo caso, no puede convertirse en la regla general. Como gráficamente ha recordado P. Salvador Coderch, "la democracia y sus reglas no siempre coinciden con la libertad y las suyas ${ }^{26}$ y el deseo de trasladar la organización democrática al mundo asociativo no puede hacerse a costa de la libertad de quienes deciden asociarse ${ }^{27}$. Como este mismo autor recuerda, G. Teubner ha sugerido y parece un criterio constitucionalmente adecuado-que "la sujeción a un estatuto democrático debe imponerse a aquellas asociaciones que representan intereses sociales ante las instancias públicas, a fin de procurar la mayor autenticidad posible en esa representación ${ }^{28}$. Resulta, por ello, criticable que la LODA imponga a todas las asociaciones por ella reguladas un régimen de democracia interna ${ }^{29}$ y aunque, desde luego, no puede entenderse como una exigencia para cualquier tipo de entidad nacida al amparo del art. $22 \mathrm{CE}$, hay que recordar que la LODA regula un tipo de asociación muy básico que debe servir para dar respuesta a fenómenos asociativos de muy diversa índole ${ }^{30}$.

\section{LA ILICITUD DE LAS ASOCIACIONESY SU CONTROL JUDICIAL}

La cuestión de la ilicitud de las asociaciones ${ }^{31}$, aunque muy compleja desde el punto de vista teórico, no había planteado problemas en la práctica hasta la aprobación de la nueva Ley Orgánica de Parti-

26 P. Salvador Coderch, Asociaciones, derechos fundamentales y Constitución, Madrid, 1997, pág. 15.

27 En este sentido se pronuncian J. J. SolozÁbal ECHAVARRía, «Asociación y Constitución», cit., págs. 491 y ss.; y L. Aguiar de LuQue y A. ElVIRA Perales, "El derecho de asociación. Comentario al art. 22 CE», cit., pág. 623.

28 Véase P. SAlvador Coderch, Asociaciones, derechos fundamentales $y$ Constitución, cit., pág. 132.

29 Según su art. 2.5, "la organización interna y el funcionamiento de las asociaciones deben ser democráticos, con pleno respeto al pluralismon. Se ignora, sin embargo, que esta exigencia es, por sí misma, una limitación del pluralismo que proclama.

30 Una valoración crítica, aunque de manera matizada, de la exigencia de la LodA en J. Gonzalez Pérez y G. Fernández Farreres, Derecho de Asociación, cit., págs. 127 y ss.

31 Recientemente se ha ocupado del tema E. Vírgala ForURIA, "Las asociaciones inconstitucionales", en R. MORODO y P. DE VEGA, Estudios de Teoría del Estado y Derecho Constitucional en honor de Pablo Lucas Verdú, México-Madrid, tomo III, págs. 1991 y ss. 
dos Políticos, que ha suscitado un amplio y bien conocido debate sobre los supuestos en los que la disolución de un partido es constitucionalmente posible. De todas formas, este debate ha arrojado poca luz sobre el alcance de la prohibición el art. 22.2 CE, pues la cuestión que se suscitó -y en la que se centró la STC 48/2003, que resolvió el recurso de inconstitucionalidad interpuesto contra la Ley por el Gobierno vasco - fue precisamente la de "si la regulación constitucional de los partidos políticos admite o no en nuestro ordenamiento un régimen legal específico y distinto del que es propio de las asociaciones", cuestión que fue contestada afirmativamente por elTribunal Constitucional en los fundamentos jurídicos $5 .^{\circ}$ a $7 .^{\circ}$, examinándose en consecuencia la Ley desde la perspectiva de lo que el partido tiene de específico frente a la simple asociación.

EI art. 22 CE ha enumerado de forma taxativa las asociaciones constitucionalmente prohibidas ${ }^{32}$ : las asociaciones secretas y paramilitares (apartado 5) y las que tengan fines o utilicen medios tipificados como delitos (apartado 2). Además, el apartado 4 establece la garantía jurisdiccional: la disolución sólo puede acordarse por un órgano judicial; se trata de una solución en cierto modo peculiar y fruto, posiblemente, de nuestra experiencia histórica, que no existe en otros países de nuestro entorno ni en la jurisprudencia del Tribunal de Estrasburgo, que admiten la disolución gubernativa, siempre, claro está, que sea revisable jurisdiccionalmente.

De acuerdo con lo dispuesto en el art. 22.2 CE "las asociaciones que persigan fines o utilicen medios tipificados como delitos son ilegales". Este precepto se viene entendiendo en el sentido de que sólo puede disolverse una asociación por la comisión de delitos y en un proceso penal, de manera que se excluye de raíz la ilicitud derivada de motivos ideológicos. Por su parte, el art. 515 del Código Penal tipifica el delito de asociación ilícita y enumera las asociaciones que tienen tal consideración, incluyendo entre ellas las de carácter paramilitar (no así las secretas que quedan, por tanto, como las únicas asociaciones constitucionalmente prohibidas pero no delictivas).

La identificación de la prohibición constitucional con la penal suscita, no obstante, algunas dificultades que, cuanto menos, convie-

32 Lo que no impide que una asociación pueda $-y$ deba - ser disuelta cuando, sin incurrir en ninguna de esas causas, incumpla las condiciones previstas en la legislación sobre el tipo asociativo de que se trate [así parece que debe entenderse la previsión del art. $\mathbf{3 8 . 2}$ b) LODA]. 
ne dejar apuntadas. Dificultades, en primer lugar, de tipo práctico, pues no es fácil determinar cuándo la conducta delictiva de personas físicas-puede imputarse a la asociación en cuanto tal. Salvo en la hipótesis poco probable de que el fin estatutariamente previsto coincida con alguna de las conductas tipificadas en el Código Penal (en cuyo caso no podrá procederse a la inscripción, y así lo ha previsto el art. 30.4 LODA) será entonces necesario acreditar que la conducta delictiva es el fin real de la asociación (o, al menos, uno de los fines), lo que deberá siempre deducirse de la actividad desarrollada por sus órganos o por sus miembros. Por otra parte, no bastará con que alguno o algunos de los miembros cometan delitos, sino que será necesario que esa actuación aparezca como cumplimiento de la voluntad del ente asociativo y que esos comportamientos marquen de alguna manera la vida asociativa. Estas dificultades prácticas (a las que hay que añadir la dificultad de condenar a todos los fundadores, directivos, miembros activos, etc., como determina el art. 517 CP) pueden explicar el escaso número de veces que este tipo penal es aplicado y parece que estuvieron en la base de la aprobación de la nueva Ley de Partidos.

Una segunda cuestión, de más calado teórico, es la de si la remisión a los fines $y$ actividades tipificados como delito debe entenderse hecha de manera exclusiva a aquellas conductas que son también delictivas para los particulares o si puede el legislador tipificar comportamientos de las asociaciones que, sin embargo, sean lícitos para la persona física. Aunque no cabe descartar a priori la legitimidad de castigar penalmente determinadas conductas, inocuas cuando las realiza una persona aislada pero que pueden ser peligrosas si se crea una estructura con tal finalidad ( $y$ de hecho esto es lo que ocurre en el art. $515 \mathrm{CP}$, que ha incluido entre las asociaciones ilícitas "las que, aun teniendo por objeto un fin lícito, empleen medios violentos o de alteración o control de la personalidad para su consecución"), no puede tampoco desconocerse que si la Constitución no excluye del derecho de asociación más que determinados supuestos, cuya enumeración debe considerarse tasada, una interpretación a sensu contrario debe llevar a la conclusión de que, fuera de esos casos, la asociación se encuentra en el ámbito constitucionalmente protegido, lo que parece incompatible con su consideración como asociación ilícita a los efectos penales. Aceptar la postura contraria, significaría remitir al Código Penal la determinación del ámbito constitucionalmente protegido por el derecho, lo que a todas luces no es compatible con al Constitución. 
La última cuestión atañe a la vía procesal para proceder a la disolución. Habitualmente se viene entendiendo que puesto que el art. 22.2 CE se refiere a la ilicitud penal, sólo en un proceso de esta naturaleza puede procederse a disolver una asociación. Es dudoso, sin embargo, que esta interpretación se imponga como una consecuencia necesaria de la Constitución. Por una parte, porque no es claro que el art. 22.2 CE encierre un mandato de tipificación penal: el legislador puede, evidentemente, calificar como delito el mero hecho de asociarse para cometer fines ilícitos, pero la sanción que de la Constitución se deriva no tiene por qué ser necesariamente la penal; lo que esta parece exigir es la disolución ${ }^{33}$. Por otro lado, desde la perspectiva del art. 22.2 CE no se trata de determinar si existe o no un delito de asociación ilícita sino de precisar si, a la vista de los comportamientos de la asociación (es decir, de sus órganos rectores) y de sus socios, puede concluirse que sus fines o sus medios son delictivos, y ello puede hacerse en un procedimiento de naturaleza distinta. En la medida en que una asociación será ilícita fundamentalmente por sus actividades (la ilicitud penal de los fines derivada únicamente de sus estatutos no resulta fácilmente imaginable), bastaría con imponer las penas correspondientes a quienes las realizan (lo que a su vez es más respetuoso con el principio de culpabilidad) y con introducir siempre que sea necesario en determinados tipos la agravante de actuar de manera organizada. El proceso contra la asociación sería, sin embargo, un proceso de limitación del derecho fundamental de asociación, en el que se trataría sólo de determinar si, de acuerdo con los criterios antes señalados, determinadas conductas de los miembros, castigadas ya penalmente por sentencia firme, pueden imputarse a la asociación en cuanto tal. $Y$ de tal proceso podrian conocer los Jueces y Tribunales no penales o, en todo caso, por un procedimiento no penal ${ }^{34}$. Quizás desde esta perspectiva se hubiera podido justificar de manera más clara la constitucionalidad de la Ley Orgánica de Partidos Políticos.

33 Aunque, cuando la ilicitud se derive del comportamiento delictivo de quienes integran los órganos de la asociación o de simples miembros, se deban imponer a estos las penas que en cada caso correspondan.

34 Un tratamiento sugerente del alcance de los apartados 2 y 4 del art. 22 $C E$, aunque desde una perspectiva diferente a la que aqui se expone, se contiene en L. M. DiEz-PICAZO, "Sobre la Constitucionalidad de la Ley Orgánica de Partidos Políticos", Repertorio Aranzadi del Tribunal Constitucional, núm. 15, 2002, págs. 21 y ss. 


\section{DERECHO DE ASOCIACIÓNYTIPOS ASOCIATIVOS. LA FUNCIÓN DE LA LEY EN EL DESARROLLO DEL DERECHO DE ASOCIACIÓN}

Para aproximarse a la compleja cuestión del papel de la ley en el ámbito del derecho de asociación, es necesario tener en cuenta que si bien se trata prima facie de un derecho de libertad que, en cuanto tal, no requiere la mediación del legislador, de su ejercicio nace una nueva organización hacia la cual el Ordenamiento no puede ser indiferente. Las organizaciones, en general, y la asociación, en particular, son ámbitos vitales que se encuentran penetrados por el Derecho, también $-y$ quizás habría que afirmar que sobre todo- por el Derecho infraconstitucional. La organización nacida de la libertad individual pretende ser reconocida como tal por el ordenamiento, operar en el tráfico jurídico y alcanzar determinados fines, y ello requiere la mediación del legislador. Por otra parte, a éste le corresponde establecer tipos de asociaciones así como precisar los requisitos para su creación y los aspectos relevantes de la organización interna y de las relaciones con terceros.

Las implicaciones entre el derecho de asociación y la determinación de los tipos asociativos son, sin duda, complejas y apenas si han merecido la atención de nuestra doctrina. Del art. 22 CE surge el derecho a constituir - sin necesidad de que medie ley alguna - una entidad asociativa. Pero, al mismo tiempo, la plena efectividad del derecho pasa porque el legislador regule diversos tipos asociativos, tales como los partidos políticos, sindicatos, asociaciones empresariales, deportivas, religiosas, etc. El ordenamiento conforma tipos asociativos y no puede negarse que toda configuración por alguien distinto del titular de la libertad la condiciona; además, quien se acoge a un determinado tipo legal verá limitada en buena medida su capacidad de autodeterminación. Sin embargo, la regulación de los tipos de asociación no puede entenderse como una limitación del derecho $y_{1}$ ni siquiera, como una labor de desarrollo a los efectos del art. 81.1 CE, lo que no quiere decir, evidentemente, que en esa labor el legislador no venga limitado por el art. $22 \mathrm{CE}$, pues debe haber una dotación mínima reconocida a cualquier entidad nacida del ejercicio del derecho $y$ se debe garantizar, en todo caso, la autonomía de la asociación para la formación de su voluntad, pues como se ha visto, se trata de un contenido indeclinable de la vertiente colectiva del derecho.

Aunque la exposición de estas cuestiones requeriría un tratamiento que excede del propósito de estas páginas (en las que se trata de dar una visión general de las cuestiones suscitadas en torno al 
derecho de asociación en estos veinticinco años), me parece que este planteamiento arroja alguna luz sobre la relación - en todo caso complicada-entre la ley orgánica y la ley ordinaria en las asociaciones $y$, con ello, sobre las funciones de la ley estatal y la ley autonómica, cuestión que se suscitó a la hora de elaborar la LODA reguladora del derecho de asociación y que previamente había sido objeto de la STC 173/1998, que resolvió el recurso de inconstitucionalidad interpuesto por el Presidente del Gobierno contra la Ley vasca de asociaciones ${ }^{35}$.

Hay que distinguir, en primer lugar, entre el desarrollo del derecho y la regulación de los tipos asociativos ${ }^{36}$. Lo primero está reservado a ley orgánica, lo segundo $\mathrm{no}^{37}$. Así lo ha entendido el autor de la LODA, que ha calificado como orgánicos unos pocos preceptos de la Ley ${ }^{38}$. El segundo problema es, entonces, determinar qué queda reservado a la Ley Orgánica. Esta fue la tarea que abordó en la STC $173 / 1998$, según la cual «...debe considerarse reservado a la ley orgánica ex art. 81.1 C.E. la regulación de "los elementos esenciales de la definición" del derecho de asociación o, en otras palabras, la delimitación de "los aspectos esenciales del contenido del derecho" en lo tocante a la titularidad, a las facultades elementales que lo integran en sus varias vertientes (STC 101/1991, fundamento jurídico $2 .{ }^{\circ}$ ), al alcance del mismo en las relaciones inter privatos, a las garantías fundamentales necesarias para preservarlo frente a las injerencias de los poderes públicos $y$, muy especialmente, dada su naturaleza de derecho de libertad, corresponde en exclusiva al legislador orgánico la precisión de los límites que, en atención a otros derechos y libertades

35 Véase, sobre el tema, E. LucAs MURILLO dE LA CUEVA, Igualdad y autonomía. Las competencias sobre asociaciones en la jurisprudencia constitucional, Madrid, 1999.

36 Aunque es evidente que en la práctica ambos extremos están estrechamente relacionados y que determinados aspectos de la regulación de un tipo concreto pueden afectar al desarrollo del derecho.

37 Según el Tribunal Constitucional «...la reserva de la Ley Orgánica en el artículo 81.1 de la Constitución en orden a las leyes relativas "al desarrollo de los derechos fundamentales" se refiere en este caso a la Ley que desarrolle el derecho fundamental de asociación en cuanto tal, pero no excluye la posibilidad de que las leyes ordinarias incidan en la regulación de tipos específicos de asociaciones, siempre que respeten el desarrollo efectuado en la Ley Orgánica" (STC 67/1985, FJ $\left.3 .{ }^{\circ}\right)$.

38 El Consejo de Estado había ido más allá, recomendando en su Dictamen sobre el Proyecto de Ley Orgánica, de 9 de mayo de 2001, que se dictarán dos normas distintas: una ley orgánica sobre el derecho de asociación y otra ley (ordinaria) de asociaciones, propuesta que no fue seguida por el legislador. 
constitucionalmente reconocidos y respetando siempre el contenido esencial, puedan establecerse para determinar las asociaciones constitucionalmente proscritas -es decir, las ilegales, secretas y de carácter paramilitar-, así como los límites en relación al derecho de asociarse de determinados grupos de personas - militares, jueces, etc.-, o en relación a la libertad de no asociarse" (FJ 8. $\left.^{\circ}\right)^{39}$. Fuera de estas materias, es el legislador ordinario el competente para regular los distintos tipos asociativos. Ese legislador será el autonómico cuando tenga asumidas competencias sobre determinados tipos de asociaciones. Su libertad de decisión viene, no obstante, limitada por las competencias que corresponden al Estado en virtud del art. 149.1.1 CE: «parece fuera de toda duda - se afirma en la misma STC 173/1998, FJ 9. que, por su conexión con el derecho de asociación y por su carácter de "requisitos mínimos indispensables" que posibilitan su ejercicio, el legislador estatal podrá considerar "condiciones básicas» ex art. 149.1.1 C.E., tanto lo que podriamos denominar la definición del concepto legal de asociación, como aquellos aspectos concretos de lo que hemos llamado régimen jurídico externo de las asociaciones (nacimiento de la personalidad, capacidad jurídica y de obrar, régimen de responsabilidad y causas y efectos de la disolución), que resulten "imprescindibles o necesarios" en orden a asegurar la igualdad de todos los españoles en el ejercicio del derecho de asociación $y$, en cuanto tales, requieren un tratamiento uniforme».

39 La enumeración es discutible y, de hecho, cabría entender que buena parte de la labor de desarrollo del derecho ha sido asumida por el propio constituyente, que en el art. $22 \mathrm{CE}$ ha regulado con cierto detalle el régimen esencial de toda asociación. 